\title{
Exploring HIV-Related Stigma and Discrimination at the Workplace in Southwestern Uganda: Challenges and Solutions
}

\author{
Benedict Twinomugisha $\mathbb{D}^{1}{ }^{1}$ Fungisai Gwanzura Ottemöller, ${ }^{2}$ and Marguerite Daniel $^{2}$ \\ ${ }^{1}$ School of Psychology, Makerere University, Kampala +256 , Uganda \\ ${ }^{2}$ Department of Health Promotion and Development, University of Bergen, Bergen +47 , Norway \\ Correspondence should be addressed to Benedict Twinomugisha; benedicttwino@gmail.com
}

Received 11 August 2020; Revised 20 October 2020; Accepted 26 October 2020; Published 11 November 2020

Academic Editor: Hamidreza Karimi-Sari

Copyright (c) 2020 Benedict Twinomugisha et al. This is an open access article distributed under the Creative Commons Attribution License, which permits unrestricted use, distribution, and reproduction in any medium, provided the original work is properly cited.

\begin{abstract}
Globally, the HIV/AIDS pandemic continues to have an enormous impact on affected societies. Despite several health promotion interventions being carried out, HIV/AIDS remains a major cause of deaths in low and middle income countries. At the workplace, the pandemic has brought about reduction in productivity, increased staff turnover, increased production costs, high levels of stigma, etc. HIV stigma is one of the main reasons why the pandemic has continued to devastate a number of societies around the world. HIV stigma presents barriers to HIV prevention in different settings including the workplace. Unlike large enterprises, small-scale enterprises have received less attention in the fight against HIV/AIDS. This study's purpose was to explore how employers and employees can overcome challenges of HIV-related stigma at the workplace. This study employed a qualitative case study design. Data were collected from eighteen participants in three small-scale enterprises in Kabale. Findings indicate that small-scale enterprises are faced with the fear of HIV testing, status disclosure, staff turnover, suicidal thoughts, gossip, etc. Implementing operative national HIV workplace policies may enable small-scale enterprises to overcome challenges of HIVrelated stigma at the workplace.
\end{abstract}

\section{Introduction}

Globally, the HIV/AIDS pandemic continues to impact most affected societies. UNAIDS global data from 2017 estimated 36.9 million people to be living with HIV/AIDS [1]. The same report revealed that 1.8 million people became newly infected with HIV in 2017. Despite several health promotion interventions being carried out, HIV/AIDS remains a major cause of deaths in low and middle income countries [2]. Unlike other infectious diseases, HIV/AIDS has become a challenge at different levels of society in general $[3,4]$ and to workplaces in particular because it affects persons of working age [5-7]. Along with other settings like school, hospital, and city, the workplace has been established as one of the priority settings for health promotion in the $21^{\text {st }}$ century [8]. The workplace is where workers congregate and spend a major portion of their waking hours, a situation that makes it suitable for health promotion programs [9]. It offers an ideal setting and infrastructure to support the promotion of health to a large audience $[8,9]$. According to Kumar and Preetha [10], health promotion efforts can be directed towards prioritized health conditions in settings-based designs such as the workplace. HIV/AIDS has brought about reduction in productivity, increased staff turnover, increased production costs, et cetera, in workplaces, due to its related illness and deaths [11-13]. It has also led to the rise of stigma and discrimination in workplaces [5, 13, 14]. UNAIDS [15] defines HIV stigma as a process of devaluation of people either living with or associated with HIV and AIDS. Discrimination is a consequence of the HIV stigma [16]. It is viewed as a stigma in action [17]. HIV-related stigma and discrimination continue to undermine the efficiency of national efforts to prevent and control the pandemic, especially in Sub-Saharan Africa $[18,19]$.

Sub-Saharan Africa (SSA) carries a disproportionate burden of the HIV pandemic, accounting for more than $70 \%$ 
of the global burden [1, 20]. In 2017, the region had 25.7 million people living with HIV/AIDS and over $70 \%$ died from HIV/AIDS-related causes [21]. With regard to the spread of HIV infections in the region, many people are affected by either AIDS-related deaths or illness [22]. But according to a UNAIDS report, SSA has made the most progress against HIV by cutting down the rate of new infections by $30 \%$ in contrast to the global average of $18 \%$ [23]. The literature on the region reveals the existence of HIV workplace policies in large companies and enterprises as an important tool in addressing the pandemic [7, 24]. However, this is not the case among small-scale enterprises, as most of them do not have HIV workplace policies [7, 25]. Small-scale enterprises, sometimes called small and medium enterprises (SMEs) employ $90 \%$ of the working age population in the region [26]. Hence, the majority of Africa's economic growth is dependent on small-scale enterprises [27]. In many SSA countries, small-scale enterprises play a crucial role in addressing poverty, inequality, unemployment, etc. That is, they provide income generating opportunities for often-disadvantaged groups in the population, such as youths and women, who may not have qualifications or opportunities for employment in formal sectors [28]. For instance, in South Africa, small-scale enterprises account for about $84 \%$ of private employment [29]. In Uganda, smallscale enterprises contribute to approximately $75 \%$ of Uganda's GDP and employ approximately 2.5 million people [30].

Uganda is among the Sub-Saharan African countries that have been hard hit by HIV/AIDS [31, 32]. Preliminary findings of the Uganda Population-based HIV Impact Assessment (UPHIA) estimated the prevalence of HIV among adults aged 15-64 at 6.2\% [33]. According to the Uganda Ministry of Health (UMoH), HIV prevalence among people of working age [15-49] is 3.7\% [6]. They represent roughly half of the population affected by HIV/AIDS, and it is thus important to target them for HIV prevention [20]). Moreover, developing countries like Uganda employ $90 \%$ of this age group in small-scale enterprises [26, 34, 35]. Notwithstanding the critical role played by small-scale enterprises in Uganda, small-scale enterprises are faced with numerous challenges including the impact of HIV/AIDS, stringent insurance requirements, limited technical and management skills, and competition from large enterprises [36]. Though small-scale enterprises may not have such infrastructure to support health promotion as large enterprises, they also lack the knowledge to initiate and sustain vital health promotion initiatives $[9,37]$ such as antidiscriminatory HIV workplace policies. Nevertheless, a study conducted among small-scale enterprises in Uganda suggested that implementing antidiscriminatory workplace programs while involving all stakeholders could yield low levels of HIV stigma and discrimination [25].

HIV-related stigma and discrimination in workplaces are prevalent in most affected societies [38]. The prevalence prompted the International Labour Organisation (ILO) through its Code of Practice on HIV/AIDS and the World of Work to pledge to overcome stigma and discrimination in the workplace [39]. The code states "HIV/AIDS is a workplace issue, not only because it affects the workforce, but also because the workplace can play a vital role in limiting the spread and effects of the epidemic. Ideally, there should be no discrimination or stigmatisation against workers on the basis of real or perceived HIV status" [39]. In the same way, the Uganda Ministry of Public Service (UMoPS) adopted an HIV workplace policy in an effort to reduce $\mathrm{HIV}$-related stigma and discrimination that affects its employees. The policy stipulates, "Public officers living with HIV/AIDS shall be protected against stigmatisation and discrimination at the workplace" [40]. One of the principles of the Uganda National HIV Policy states, "the ethic of nondiscrimination to anyone on the basis of their HIV/ AIDS status shall be enforced and promoted by all service providers" [41]. However, the policy does not specify how employers/organisations should address HIV-related stigma and discrimination in workplaces.

Research indicates that HIV-related stigma and discrimination present major barriers to HIV/AIDS prevention, treatment, and care in the workplace setting $[19,42,43]$. This is largely because stigma and discrimination hinder the uptake of HIV/AIDS counselling and testing among employees in workplaces $[16,18,44]$. In the workplace, employees may suffer from HIV-related stigma and discrimination from their coworkers and supervisors/employers in the form of social isolation, ridicule, and termination of employment [45]. Some enterprises adopt selection criteria that stigmatise those found HIV positive [46]. For example, a study conducted in South Africa revealed that half of the respondents had lost their jobs in the preceding 12 months due to their HIV Sero-status [14]. In Botswana, HIV stigma is one of the barriers to accessing ARVs [47]. In Kenya, HIV stigma has hindered infected health workers from disclosing their HIV status [48]. In Uganda, HIV stigma has hampered small workplaces in the fight against HIV/AIDS [25]. Conversely, the issue of stigma and discrimination is a double-edged sword because not only do employers who are infected fear being stigmatized by their employees [49], they are also afraid of diminishing productivity amongst their employees due to increased absenteeism and high staff turnover [34, 49, 50].

Four decades into the pandemic, HIV-related stigma and discrimination still hinder individuals and communities from accessing and benefiting from effective prevention and treatment programs $[51,52]$. Studies addressing HIV stigma and discrimination have been conducted in affected communities $[18,53]$. A study conducted in Ghana found that encouraging people to go for HIV counselling and testing helped in overcoming HIV-related stigma and discrimination [54]. In Uganda, program implementers argued that increasing availability of antiretroviral therapy will help in reducing HIV stigma [55, 56]. Pulerwitz and colleagues [57] noted that responding to the needs of stigmatized populations, involving people living with HIV/AIDS (PLHA) in service delivery and engaging the community contributed to efforts directed at reducing HIV stigma. Indeed, overcoming stigma requires an understanding of the associated factors, such as people's increased knowledge of how PLHA combat stigma [38, 52]. Whereas a number of research studies on $\mathrm{HIV}$-related stigma and discrimination have been conducted 
in different settings and large enterprises in Uganda [58-61], research on HIV-related stigma and discrimination in smallscale enterprises remains scanty. This shortage could be a starting point at designing HIV prevention interventions in small-scale enterprises. The shortage may also explain why small-scale enterprises in Uganda have been left out in the fight against HIV/AIDS [25]. Though most scientific work about HIV-related stigma and discrimination focuses on challenges rather than strategies to overcome it, studies that identify strategies to reduce HIV-related stigma and discrimination are equally important [52]. Stigma-reduction work has shown the importance of in-person training, an approach that is intended to create safe spaces for the contact between healthcare workers and PLHA [62].

In this paper, therefore, we explore how employees and their employers in Southwestern Uganda can overcome challenges of HIV-related stigma and discrimination in small-scale enterprises. Specifically, we address two research questions: (i) What are the challenges faced by employees and employers due to HIV-related stigma and discrimination at the workplace? (ii) How can small-scale enterprises overcome the challenges of HIV-related stigma and discrimination at the workplace?

\section{Materials and Methods}

2.1. Study Design. This study employed a qualitative research design that utilized a case study approach. Case studies "explore a program, event, activity, process, or one or more individuals in-depth" $[63,64]$. We chose a case study because it enables researchers to explore and understand the meanings of individuals or groups ascribe to a social or human problem [64]. In this study, our case was three smallscale enterprises. We utilized a qualitative case study design because it provides the researcher with an opportunity to probe further (using "why," "what," "how" questions) the phenomenon under investigation [64].

2.2. Study Participants and Setting. Data were collected from 18 respondents purposively selected from three small-scale enterprises. The enterprises were geographically located in Southwestern Uganda where the prevalence of HIV/AIDS among adults aged 15-64 was estimated at 7.9\% [33]. We applied a purposive sampling procedure because our study was limited to employees and employers in small-scale enterprises. Respondents were categorised into three groups: employees, supervisors, and employers as shown in Table 1. Out of the eighteen respondents, eleven were men and seven were women. The types of small-scale enterprises visited were Carpentry (Cap), Bakery (Bak), and Matchbox factory (Mat). All three enterprises employed 5-15 employees on a part-time basis at the time of the interviews. This limited the number of recruited respondents because a few employees could be found at the workplace at any given time.

2.3. Study Procedure. Before actual field work commenced, the first author (BT) contacted his former colleague that was working in Kabale district, Southwestern Uganda. The main
TABle 1: Demographic information.

\begin{tabular}{lccc}
\hline Item & Group & Number & Total \\
\hline \multirow{2}{*}{ Sex } & Men & 11 & 18 \\
& Women & 07 & \\
\hline \multirow{3}{*}{ Job description } & Employees & 14 & 18 \\
& Supervisors & 01 & \\
& Employers & 03 & \\
\multirow{3}{*}{ Type of enterprise } & Carpentry & 05 & 18 \\
& Matchbox factory & 07 & \\
& Bakery & 06 & \\
\hline
\end{tabular}

intention of the communication was to establish a contact person to guide and identify five small-scale enterprises to participate in the study. Out of the five small-scale enterprises contacted, only three enterprises agreed to participate in the study. The other two enterprises did not give reasons as to why they declined to participate. All the three employers (in their respective enterprises) were visited by $\mathrm{BT}$ at their workplaces before actual data collection. Of the three employers who agreed to participate in our study, one employer delegated a senior staff member (supervisor) to participate. After conducting an interview with an employer, he/she would introduce BT to his/her employees from their specific units/ departments. Each employee was approached and purposively selected to participate depending on his/her interest and on whether they were available to take part in the study.

2.4. Instruments and Measures. The first author (BT) collected data using in-depth interviews to explore the challenges of HIV-related stigma and discrimination and their solutions. The in-depth interview guide comprised questions such as Why do some employees fear to test for HIV? Why do some employees fear to disclose their HIV status? How can employers and employees overcome the challenges of HIV-related stigma at the workplace? In-depth interviews enabled us to obtain in-depth information from a total of 18 respondents. These were conducted in an environment (all study sites had a private room) suitable for interviews. On average, each interview lasted for 50 minutes. Depending on the choice of our respondents (employees and employers), all interviews were conducted in either Rukiga (local language) or English but were noted down in English.

2.5. Data Analysis. The process of data analysis began with transcribing data, followed by inductive coding. Codes were then categorised deductively into both descriptive and analytical codes using themes developed from the in-depth interview guide such as challenges of HIV-related stigma and discrimination as seen in Table 2. Grouped coded data were later analysed thematically using Creswell's six steps of qualitative data analysis [64].

2.6. Ethical Considerations. The study was approved by the Uganda National Council for Science and Technology (UNCST). We ensured that all respondents were provided with two written informed consent forms. Before BT began 
TABle 2: An example of organisation of data by tabulation (employees).

\begin{tabular}{|c|c|c|c|}
\hline $\begin{array}{l}\text { Theme 1: challenges of HIV-related stigma and } \\
\text { discrimination }\end{array}$ & Respondents & Descriptive codes & Analytical codes \\
\hline \multirow{2}{*}{$\begin{array}{l}\text { Subtheme 1: reasons why employees fear to test for } \\
\text { HIV }\end{array}$} & $\begin{array}{l}\text { L, O, S, V } \\
\text { N, Q, R, Y }\end{array}$ & $\begin{array}{l}\text { Fear for HIV-related problems/issues, fearing discrimination } \\
\text { from coworkers }\end{array}$ & $\begin{array}{l}\text { HIV stigma fear } \\
\text { Fear of } \\
\text { discrimination }\end{array}$ \\
\hline & $\mathrm{T}, \mathrm{U}, \mathrm{W}, \mathrm{Z}$ & $\begin{array}{l}\text { Mainly fear to be known as HIV positive by employers, fear to } \\
\text { be chased away by employers }\end{array}$ & Fear to disclose \\
\hline \multirow{2}{*}{$\begin{array}{l}\text { Subtheme 2: the workplace is a good environment } \\
\text { for one to take HIV test }\end{array}$} & $\begin{array}{l}\text { Y, Z,W, P, } \\
\text { N, U, T }\end{array}$ & $\begin{array}{c}\text { Never advised to utilise the workplace, unknown motives, ever } \\
\text { busy to discuss with us }\end{array}$ & $\begin{array}{l}\text { Underutilised setting, } \\
\text { lack of cooperation }\end{array}$ \\
\hline & $\begin{array}{l}\mathrm{U}, \mathrm{O}, \mathrm{R}, \mathrm{X} \\
\mathrm{V}, \mathrm{W}\end{array}$ & Limited informal HIV talk, our productiveness & $\begin{array}{l}\text { Poor working } \\
\text { relationship }\end{array}$ \\
\hline
\end{tabular}

the interviews, he asked the respondents to read the informed consent form. He then explained the purpose of the study emphasising that participation was voluntary and that they could withdraw from the study at any time. He assured the respondents that all data collected would be kept confidential. Anonymity was ensured in transcriptions by using identifiers such as "Cap-Emp-M," "Employer-A" instead of a respondent's name. Two copies of the written informed consent forms were signed by BT and the respondent, and each respondent retained a copy. Due to the sensitive nature of the topic and the dynamics of small-scale enterprises, we ensured privacy by conducting each interview in a reserved room in each of the three selected small-scale enterprises.

\section{Results}

The presentation of our findings is structured under two main themes that emerged through data analysis, namely, challenges and solutions. Based on our findings from 18 respondents, challenges of $\mathrm{HIV}$-related stigma and discrimination in small-scale enterprises continued to emerge. Although views from 18 respondents may not represent all employees and employers in small-scale enterprises in the whole country, lessons concerning challenges related to HIV/AIDS stigma and discrimination and suggestions on how to overcome them can be learnt from this study.

3.1. Challenges. A majority of the respondents revealed that HIV-related stigma and discrimination create fear for HIV/ AIDS testing among employees at the workplace. Similar to their employees, the three employers who participated in this study confirmed that their employees fear to test for HIV/AIDS due to fear of being stigmatised by fellow employees:

"Some employees fear to test for HIV/AIDS because they do not want co-workers to know their HIV/AIDS status" (Cap-Emp-L).

"I think some employees fear to test for HIV/AIDS [...] they do not want their fellow staff to know that their status [...], may be stigmatised by fellow staff" (Employer-B).

The findings of this study revealed that employees fear to disclose their HIV test results because they are afraid of being stigmatised and discriminated against in the workplace by employers.

"[...] some employers end up losing staff who declare to be $H I V$ positive, due to HIV stigma, some HIV positive employees leave the enterprise after their disclosure [...]" (CapEmp-M).

"I would not share my results with my employer [...] In case of any he may end up disclosing my HIV status to everybody" (Cap-Emp-L).

"Some workers do not want anybody to know their HIV status [...] they do not want to disclose their status due to fear of discrimination by employers" (Employer-A).

Employees and employers further revealed that some small-scale enterprises face the challenge of staff turnover and loss of prospective employees as some employers insist on knowing their employees' and job applicants' HIV status. Both employees and employers consented that the two challenges equally affect employers and employees:

"Due to stigma, employers lose hardworking staff [...] prospective employees may shun an enterprise after being stigmatised during recruitment" (Mat-Emp-Q).

"Due to stigma, we may lose good staff [. . ]; one may not come back to work after he has been stigmatised and discriminated" (Employer-C).

Regarding testing employees from their workplaces, one of the employers who participated in this study disagreed and revealed that small-scale enterprises might not afford to maintain confidentiality attached to HIV test results. It was revealed that healthcare providers carrying out HIV testing could at the same time bleach confidentiality:

"The workplace is not a good place for one to take an HIV test. [...] those carrying out the test may disclose the results" (Employer-B).

Our results showed that HIV-related stigma and discrimination had created hostile/challenging work environments characterised by rumour mongering, loneliness, isolation, misunderstandings, role conflict, occupational stress, etc.

"[...] because of gossiping about their co-workers, you find that some employees want to fight each other [...], some employees do not talk to each other" (Mat-Emp-R).

"We find it challenging to sustain two groups of employees [...] and to keep them productive" (Employer-A). 
A few of the employees and employers highlighted that some employees in small-scale enterprises are faced with suicidal thoughts after testing HIV positive. It was revealed that after testing HIV positive, some youths perceive such HIV positive results as an end to their employment and lives. Some employees who test positive lose hope and start thinking about committing suicide:

"These youths lose hope and develop suicidal thoughts after testing HIV positive. I have heard it from some of our coworkers here [...]" (Bak-Emp-W).

"I do not support employers who deny their employees employment after testing HIV positive; one may completely lose hope and commit suicide?" (Employer-B).

Contrariwise, when asked about the approach of workplace-based HIV testing, a number of employees were comfortable with the idea of HIV testing from the workplace:

"As workers we all need to test from here and know our HIV status as a group [...], that we are safe or not" (BakEmp-Y).

"[...], it is ok, it is good to test and know my status. [...] I am okay with testing from here, my HIV status is mine alone" (Mat-Emp-S).

3.2. Solutions. In relation to the above challenges, this study indicated that employees and employers in small-scale enterprises are willing to support each other in an effort to curb down fears related to HIV testing at the workplace.

"After testing for HIV, I got courage to support my coworkers by telling them to go for HIV testing so that they can know their status" (Mat-Emp-T).

"I support my employees by advising them to go for HIV testing [...], advise them to stop taking alcohol [...]" (Employer-C).

A majority of employees and employers revealed that implementing HIV workplace policies that involve all employees could reduce HIV-related stigma and discrimination in workplaces. A number of employees and employers indicated that employees should be consulted and allowed to participate in the design and implementation of HIV workplace policies. All three employers specifically revealed that cooperation between employers and employees reduces HIV-related stigma and discrimination in workplaces:

"Employees also need to be highly involved in the design and implementation of HIV workplace policies" (Cap-Emp-N).

"[...] employers should always cooperate with employees, [...] should get time to discuss with their employees" (Employer-C).

A number of employees revealed that HIV sensitization and awareness programs at the workplace could reduce HIV-related stigma and discrimination. Employees alluded that the government of Uganda should sensitize all employers on how to handle issues of HIV-related stigma and discrimination in workplaces. Similarly, employers stated that small-scale enterprises should also be considered in the fight against HIV/AIDS in workplaces. It was revealed that even small-scale enterprises deserve HIV sensitization and awareness programs:
"Employers should be sensitised so that they start sharing HIV-related issues with their employees at the workplace [...]" (Cap-Emp-O).

"[...] HIV support organisations should utilise HIV outreaches to ensure that even employees in small-scale enterprises are fully sensitised [...]" (Employer-A).

With regard to workplace-based HIV testing, some employees and employers suggested that their enterprises ought to be affiliated with nearby health centres as a way of overcoming HIV-related stigma and discrimination in workplaces:

"Employers ought to make sure that their enterprises are affiliated to near-by clinics so that workers use these facilities for some HIV-related services [...]" (Mat-Emp-T).

"Employers should always have time for their employees, take them to a nearby health facility in case of health issues especially those perceived to be positive, [...]" (Employer-C).

\section{Discussion}

In this study, we explored how employees and their employers in Southwestern Uganda can overcome challenges of HIV-related stigma and discrimination in small-scale enterprises. Whereas HIV testing is a crucial step in the fight against HIV/AIDS, some employees still fear testing for HIV at the workplace due to fear attached to HIV stigma and discrimination from coworkers and employers. Consistent with our findings, studies have revealed that most employees feared testing for HIV at the workplace due to fear of HIV stigma and discrimination by coworkers and by employers $[16,18,46,65]$. However, according to the international best practices and particularly the ILO Discrimination Convention [66], an employee has the right to privacy and confidentiality regarding his/her HIV/AIDS status and freedom from discrimination on the ground of the said status. In line with the convention, findings of this study indicated increased social support in terms of willingness by employees and employers to support each other in curbing down fears related to HIV testing at the workplace. In one of the studies conducted in Australia, increased social support was associated with less HIV centrality, less internalised stigma, and less psychological distress [67]. Studies conducted among medium and large sized African workplaces demonstrated that employees will be more interested in taking up HIV testing if they know there is support available in case they are found to be HIV positive $[18,68]$. As a result of HIV-related stigma and discrimination, some individuals are denied necessary social support $[44,69]$.

Regarding the disclosure of HIV status, our study revealed that employees fear to disclose their HIV test results because they are afraid of being stigmatised and discriminated against in the workplace. Also, a study conducted in the Netherlands by Stutterheim and colleagues [70] reported that more than half of the participants were not willing to disclose their HIV status at the workplace showing that this is not only applicable to Sub-Saharan Africa. Disclosing one's HIV status at the workplace is still accompanied by fear of HIV stigma and discrimination [71, 72]. A number of 
research studies conducted in other settings in Uganda have clearly documented HIV-related stigma and discrimination as an obstacle to HIV status disclosure [59-61, 72, 73]. Equally, in Australia, nondisclosure in the workplace was much higher compared to other settings [74, 75]. Our findings highlighted the important role national HIV workplace policies could have to mitigate these fears, together with sensitization of employees and their employers, counselling, and access to treatment. These findings reinforce suggestions by Kassile et al. [18] that constant roll out of HIV/AIDS sensitization and awareness programs can reduce HIV-related stigma and discrimination.

This study revealed that some small-scale enterprises are faced with the challenge of staff turnover and loss of prospective employees due to employers who insist on knowing their employees' and job applicants' HIV status. Similarly, a study conducted in South Africa also found that employees failed to test for HIV because some employers insisted on knowing their HIV status [76]. Based on our findings, we assume that an HIV positive job applicant may not go back to the enterprise if he/she has been asked to test for HIV/ AIDS during the selection process. Without a doubt, prospective employees living with HIV/AIDS also experience HIV stigma and discrimination from employers [46]. A study carried out in South India established that some people lose jobs after being screened and found to be HIV positive [43], implying that any job applicant who tests HIV positive would be denied employment opportunities. It is unfortunate that, to date, such discriminatory behaviours still exist in some enterprises [68]. However, according to the Uganda National Policy on HIV/AIDS and the World of Work, employees or prospective employees should not be subjected to personal discrimination on the basis of real or perceived HIV/AIDS status [77].

Our findings revealed that many of the employees were in support of workplace-based HIV testing. In line with this, a study conducted among private and public sectors in Nigeria indicated workers' willingness to support various HIV/AIDS-related activities at the workplace including voluntary HIV counselling and testing [46]. Certainly, onsite voluntary HIV counselling and testing (VCT) in the workplace might be one way to improve uptake of HIV testing [78]. On the other hand, a few respondents were not in support of workplace-based HIV testing and revealed that small-scale enterprises might not afford to maintain confidentiality. Whereas workplace testing is a variant of venuebased testing that brings testing to populations that may not access care in routine settings, concerns about confidentiality during testing can undermine the acceptability of workplace-based HIV testing [79]. As a way of overcoming HIV-related stigma and discrimination in workplaces, our respondents suggested that small-scale enterprises should be affiliated or linked to nearby health facilities. In agreement with our findings, a study conducted in South Africa revealed that linkage to off-site clinics increased the number of employees that tested for HIV [80]. This means that employees in enterprises with clear HIV workplace policies and formal arrangements with health facilities can be tested safely and confidentially.
Research indicates that HIV-related stigma and discrimination affect people's lives, destabilise workplaces and HIV positive employees $[14,18]$. According to our findings, HIV-related stigma and discrimination create hostile/challenging work environments characterised by interpersonal effects such as gossip, isolation, misunderstandings, occupational stress, loss of hope, suicidal thoughts, etc. They can also exacerbate mental health problems and significantly reduce the quality of life of PLHA [59, 60, 81]. Poor interpersonal relations between employees and coworkers stir up gossip, a stigmatizing practice [82]. However, misconceptions that exist among some employers on how to relate with HIV positive workers stem from a lack of adequate information on HIV/AIDS [46]. Thus, it is crucial to destigmatize HIV/AIDS in workplaces especially through scaling up sensitization and awareness programs [61]. Furthermore, our findings highlighted that some employees in small-scale enterprises are faced with suicidal thoughts after testing HIV positive. After testing HIV positive, some people lose hope and start thinking about committing suicide as they perceive HIV/AIDS positive results to be an end to their lives $[69,83]$. In the context of prevention, relevant authorities ought to initiate and work with other stakeholders to promote HIV prevention programs, particularly in the workplace [84].

In this study, employees and employers called for employee participation/involvement in the implementation process of HIV workplace policies. The principle of participation and involvement is among the five principles of health promotion that came out clearly in this study [85]. Sustainable health promotion change can only take place if the target group has the opportunity to develop ownership of the program [85]. Based on the ILO code of practice, employers should consult with employees and their representatives to develop and implement appropriate HIV workplace policies designed to prevent the spread of the infection and protect all workers from HIV-related stigma and discrimination [84]. In line with our findings, a study carried out in Zambian enterprises confirmed the role of employee involvement in implementing HIV workplace policies [7]. Participation and involvement during the formulation, review, and implementation of the policy will perhaps create morale among employees to appreciate it and own it $[10,85,86]$. It is, therefore, important to ensure that employees benefit from such workplace policies because knowing how they benefit from a specific initiative helps policy makers to properly design and implement new and effective initiatives $[9,87]$.

\section{Limitations}

A few of the employers interviewed were reluctant to introduce their employees to BT and claimed that they would not have enough time to attend interviews. Despite a few hurdles, BT met fifteen employees who agreed to participate in the study. Most of the employees were employed on a part-time basis and residing in distant places. This yielded undesirable outcomes such as conducting interviews in the evening. Fortunately, in each enterprise that participated in 
the study, BT was allocated an illuminated private room. Study respondents expected us to distribute condoms. However, we did not have any, but we offered an explanation that this study was only for academic purposes and advised them to visit a branch of Uganda AIDS Information Centre located in Kabale town.

\section{Recommendations}

Our study indicates that there is a need to address HIVrelated stigma and discrimination in small-scale enterprises. A positive contribution in this context would be the enactment of effective and nondiscriminatory HIV workplace policies to advocate for workers' health rights. With such policies in place, employees who are afraid of going for HIV testing might overcome their fears.

National and International Nongovernmental Organisations working under the umbrella of fighting the HIV pandemic should engage all small-scale enterprises other than concentrating on large-scale enterprises.

Employers in small-scale enterprises should involve their employees while designing and implementing HIV workplace policies.

These findings further contribute to the basis for the potential methodology of utilising the workplace setting to overcome HIV-related stigma and discrimination.

\section{Conclusion}

Our study indicated that some employees fear to test for HIV/AIDS and to disclose their HIV/AIDS status because they are not sure of how they will be perceived and treated by their fellow employees and employers. Our findings demonstrated that limited confidentiality in small-scale enterprises exacerbates stigma and discrimination attached to HIV/AIDS testing and disclosure at the workplace. Similar to other settings, HIV-related stigma and discrimination have affected employees in small-scale enterprises by attaching a lot of fear to HIV testing and HIV status disclosure. The Ugandan government's support in the form of implementing operative HIV/AIDS workplace policies like the National HIV/AIDS Policy and National Policy on HIV/ AIDS and the World of Work may greatly contribute to efforts geared towards overcoming challenges of HIV-related stigma and discrimination at the workplace.

\section{Data Availability}

The processed data (in the Published Thesis) can be found at http://bora.uib.no/handle/1956/4279.

\section{Conflicts of Interest}

There are no conflicts of interest declared by the authors.

\section{References}

[1] UNAIDS, Fact Sheet-2017 Global HIV Statistics, UNAIDS, Geneva, Switzerland, 2018, http://www.unaids.org/sites/ default/files/media_asset/UNAIDS_FactSheet_en.pdf.
[2] G. Maartens, C. Celum, and S. R. Lewin, "HIV infection: epidemiology, pathogenesis, treatment, and prevention," The Lancet, vol. 384, no. 9939, pp. 258-271, 2014.

[3] M. Dahlui, N. Azahar, A. Bulgiba et al., "HIV/AIDS related stigma and discrimination against PLWHA in Nigerian population," PLoS One, vol. 10, no. 2, pp. 1-11, 2015.

[4] E. N. Kontomanolis, S. Michalopoulos, G. Gkasdaris, and Z. Fasoulakis, "The social stigma of HIV-AIDS: society's role," HIV/AIDS-Research and Palliative Care, vol. 9, pp. 111-118, 2017.

[5] P. Sonnenberg, A. Copas, J. R. Glynn et al., "The effect of HIV infection on time off work in a large cohort of gold miners with known dates of seroconversion," Occupational and Environmental Medicine, vol. 68, no. 9, pp. 647-652, 2011.

[6] Ministry of Health and Finance, Millennium Development Goals Report for Uganda: Drivers of MDG Progress in Uganda and Implications for the Post-2015 Development Agenda, Ministry of Health, Kampala, Uganda, 2013.

[7] B. Chatora, H. Chibanda, L. Kampata, and W. Mutale, "HIV/ AIDS workplace policy addressing epidemic drivers through workplace programs," Bio Med Central Public Health, vol. 18, p. 180, 2018.

[8] C. Chu, G. Breucker, N. Harris et al., "Health-promoting workplaces-international settings development," Health Promotion International, vol. 15, no. 2, pp. 155-167, 2000.

[9] L. J. Warshaw and J. Messite, "Protection and promotion in the workplace: an overview," Encyclopedia of Occupational Health and Safety Chapter 15, International Labour Organisation, Geneva, Switzerland, 1998.

[10] S. Kumar and G. Preetha, "Health promotion: an effective tool for global health," Indian Journal of Community Medicine, vol. 37, no. 1, pp. 5-12, 2012.

[11] O. Surgevil and E. Mayaturk Akyol, "Discrimination against people living with HIV/AIDS in the workplace: Turkey context," Equality, Diversity and Inclusion: An International Journal, vol. 30, no. 6, pp. 463-481, 2011.

[12] F. Simtowe and F. M. Kinkingninhoun-Medagbe, "The impact of HIV/AIDS on labour markets, productivity and welfare in southern Africa: a critical review and analysis," African Journal of Agricultural Research, vol. 6, no. 10, pp. 2118-2131, 2011.

[13] A. Davids, M. Weihs, A. Tunzi, and D. Tassiopoulos, What Works in HIV and AIDS and the World of Work in the South African and Namibian Tourism Industry at Selected Country Sites?, Human Sciences Research Council, Johannesburg, South Africa, 2017.

[14] M. L. Santos, P. Kruger, S. E. Mellors, G. Wolvaardt, and E. van der Ryst, "An exploratory survey measuring stigma and discrimination experienced by people living with HIV/AIDS in South Africa: the people living with HIV stigma index," Bio Med Central Public Health, vol. 14, p. 80, 2014.

[15] UNAIDS, Reducing HIV Stigma and Discrimination: A Critical Part of National AIDS Programmes. A Resource for National Stakeholders in the HIV Response, UNAIDS, Geneva, Switzerland, 2007.

[16] O. E. Omosanya, O. T. Elegbede, S. M. Agboola, A. O. Isinkaye, and O. A. Omopariola, "Effects of stigmatization/discrimination on antiretroviral therapy adherence among HIV-infected patients in a rural tertiary medical center in Nigeria," Journal of the International Association of Providers of AIDS Care (JIAPAC), vol. 13, no. 3, pp. 260-263, 2013.

[17] M. Nginya, P. A. Odundo, A. Kabunga, B. Ngaruiya, R. W. M. Kahiga, and E. M. Muriithi, "Effects of stigma and 
discrimination on the right to education of children with HIV/AIDS aged 4-8 years in Kikuyu sub-county, Kenya," International Journal of Elementary Education, vol. 5, no. 1, pp. 1-7, 2016.

[18] T. Kassile, H. Anicetus, and R. Kukula, "HIV/AIDS-related stigma and discrimination in workplaces in Tanzania," Medicine and Health Sciences, vol. 2, no. 1, pp. 31-41, 2015.

[19] A. B. Kharsany and Q. A. Karim, "HIV infection and AIDS in sub-Saharan Africa: current status, challenges and opportunities," The Open AIDS Journal, vol. 10, pp. 34-48, 2016.

[20] R. Mafigiri, J. K. B. Matovu, F. E. Makumbi et al., "HIV prevalence and uptake of HIV/AIDS services among youths (15-24 years) in fishing and neighbouring communities of kasensero, rakai district, southwestern Uganda," Bio Med Central Public Health, vol. 17, no. 251, pp. 2-10, 2017.

[21] World Health Organisation, HIV/AIDS, Key Facts, WHO, Geneva, Switzerland, 2018, http://www.who.int/news-room/ fact-sheets/detail/hiv-aids.

[22] M. V. Koto and P. Maharaj, "Difficulties facing healthcare workers in the era of AIDS treatment in Lesotho," SAHARA: Journal of Social Aspects of HIV/AIDS, vol. 13, no. 1, pp. 53-59, 2016.

[23] UNAIDS, Miles to Go Closing Gaps Breaking Barriers Righting Injustices. Global AIDS Update 2018, UNAIDS, Geneva, Switzerland, 2018.

[24] K. Deane, S. Stevano, and D. Johnston, “Employers' responses to the HIV epidemic in sub-Saharan Africa: revisiting the evidence," Development Policy Review Accepted Manuscript, vol. 37, no. 2, pp. 245-259, 2018.

[25] B. Twinomugisha, M. Daniel, and G. T. Lie, "We also have cases of the disease that you are researching about: SSEs and the challenges of HIV/AIDS-related stigma and discrimination in Kabale, Uganda," Health Policy and Development, vol. 9, no. 1, pp. 37-45, 2011.

[26] UNESCO, Report of the 2012 EFA Global Monitoring on Skills, Work Youth, UNESCO, Paris, France, 2012, http://www. unesco.org/new/fileadmin/2012.

[27] S. M. Muriithi, "African small and medium enterprises (SMEs) contributions, challenges and solutions," European Journal of Research and Reflection in Management Sciences, vol. 5, no. 1, pp. 36-48, 2017.

[28] G. G. Fiseha and A. A. Oyelana, "An assessment of the roles of small and medium enterprises (SMEs) in the local economic development (LED) in South Africa," Journal of Economics, vol. 6, no. 3, pp. 280-290, 2015.

[29] M. S. Akugri, D. A. Bagah, and J. K. Wulifan, "The contributions of small and medium scale enterprises to economic growth: a cross-sectional study of Zebilla in the Bawku west district of northern Ghana," European Journal of Business and Management, vol. 7, no. 9, pp. 262-274, 2015.

[30] UNAIDS, HIV/AIDS Estimates, UNAIDS, Geneva, Switzerland, 2009, http://www.unaids.org/en/countryResponse/ Countries/uganda.asp.

[31] H. Zakumumpa, S. Bennett, and F. Ssengooba, "Modifications to art service delivery models by health facilities in Uganda in promotion of intervention sustainability: a mixed methods study," Implementation Science, vol. 12, no. 45, pp. 1-14, 2017.

[32] UPHIA, Population-based HIV Impact Assessment (UPHIA 2016-2017): Summary Sheet: Preliminary Findings, UPHIA, Kampala, Uganda, 2017.

[33] O. K. Osunsan and N. Sumil, "Growth and internationalization of small enterprises in Kampala district, Uganda," World Journal of Social Sciences, vol. 2, no. 7, pp. 211-221, 2012.
[34] International Labour Organisation, HIV/AIDS and the World of Work. Fourth Item on the Agenda: International Organisation of Employers. HIV/AIDS Challenges in the Workplace: Responses by Employers' Organizations and Their Members in Africa, International Labour Organisation, Geneva, Switzerland, 2009.

[35] J. Page and M. Seoderbom, "Is small beautiful? small enterprise, aid and employment in Africa," African Development Review, vol. 27, no. 1, pp. 44-55, 2015.

[36] E. Turyahikayo, "Challenges faced by small and medium enterprises in raising finance in Uganda," International Journal of Public Administration and Management Research, vol. 3, no. 2, pp. 21-33, 2015.

[37] L. L. Andersen, K. I. Proper, L. Punnett, R. Wynne, R. Persson, and N Wiezer, "Workplace health promotion and wellbeing," The Scientific World Journal, vol. 2015, Article ID 606875, 2 pages, 2015.

[38] X. Dong, J. Yang, L. Peng et al., "HIV-related stigma and discrimination amongst healthcare providers in Guangzhou, China," Bio Med Central Public Health, vol. 18, no. 738, pp. 1-10, 2018.

[39] International Labour Organisation, ILO Code of Practice on HIV and the World of Work: HIV/AIDS and the Informal Economy, International Labour Organisation, Geneva, Switzerland, 2002.

[40] United Nations Office for Project Services, The Uganda Public Service HIV/AIDS Policy, United Nations Office for Project Services, Kampala, Uganda, 2007.

[41] Republic of Uganda, National HIV/AIDS Policy Kampala: Office of the President and Uganda AIDS Commission, Uganda AIDS Commission, Kampala, Uganda, 2011.

[42] J. R. Hargreaves, A. Stangl, V. Bond et al., "HIV-related stigma and universal testing and treatment for HIV prevention and care: design of an implementation science evaluation nested in the HPTN 071 (PopART) cluster-randomized trial in Zambia and South Africa," Health Policy and Planning, vol. 31, no. 10, pp. 1342-1354, 2016.

[43] N. Kumar, B. Unnikrishnan, R. Thapar et al., "Stigmatization and discrimination toward people living with HIV/AIDS in a coastal city of South India," Journal of the International Association of Providers of AIDS Care (JIAPAC), vol. 16, no. 3, pp. 226-232, 2017.

[44] M. Mhode and T. Nyamhanga, "Experiences and impact of stigma and discrimination among people on antiretroviral therapy in dar es salaam: a qualitative perspective," AIDS Research and Treatment, vol. 2016, Article ID 7925052, 11 pages, 2016.

[45] R. Stewart, J. Pulerwitz, and E. Esu-Williams, Addressing HIV/ AIDS Stigma and Discrimination in a Workplace Program: Emerging Findings, Population Council/Horizons, Washington, DC, USA, 2003.

[46] I. O. Dipeolu, "HIV and AIDS in workplace: the role of behaviour antecedents on behavioural intentions," African Journal of Medical Science, vol. 43, no. 1, pp. 131-140, 2014.

[47] M. Saki, M. S. Khan Kermanshahi, E. Mohammadi, and M. Mohraz, "Perception of patients with HIV/AIDS from stigma and discrimination," Iranian Red Crescent Medical Journal, vol. 17, no. 6, Article ID e23638, 2015.

[48] P. Cherutich, R. Kaiser, J. Galbraith et al., "Lack of knowledge of HIV status a major barrier to HIV prevention, care and treatment efforts in Kenya: results from a nationally representative study," PLoS One, vol. 7, no. 5, Article ID e36797, 2012. 
[49] L.-W. Chao, H. Szrek, R. Leite, S. Ramlagan, and K. Peltzer, "Do customers flee from HIV? a survey of HIV stigma and its potential economic consequences on small businesses in Tshwane (Pretoria), South Africa," AIDS and Behavior, vol. 21, no. 1, pp. 217-226, 2017.

[50] K. Verbooy, M. Wagener, M. Kaddouri et al., "Are people living with HIV less productive at work?” AIDS Care, vol. 30, no. 10, pp. 1265-1272, 2018.

[51] A. L. Stangl and C. I. Grossman, "Global Action to reduce HIV stigma and discrimination," Journal of the International AIDS Society, vol. 16, no. 2, pp. 189-234, 2013.

[52] C. T. Rael, A. Carballo-Diéguez, R. Norton et al., "Identifying strategies to cope with HIV-related stigma in a group of women living with HIV/AIDS in the Dominican republic: a qualitative study," AIDS and Behavior, vol. 21, no. 9, pp. 2589-2599, 2017.

[53] A. Olalekan, A. Akintunde, and M. Olatunji, "Perception of societal stigma and discrimination towards people living with HIV/AIDS in Lagos, Nigeria: a qualitative study," Materia Socio Medica, vol. 26, no. 3, pp. 191-194, 2014.

[54] E. Y. Tenkorang and A. Y. Owusu, "Examining HIV-related stigma and discrimination in Ghana: what are the major contributors?" Sexual Health, vol. 10, no. 3, pp. 253-262, 2013.

[55] B. T. Chan, S. D. Weiser, Y. Boum et al., "Persistent HIVrelated stigma in rural Uganda during a period of increasing HIV incidence despite treatment expansion," AIDS, vol. 29, no. 1, pp. 83-90, 2015.

[56] M. O. Kuteesa, S. Wright, J. Seeley et al., "Experiences of HIVrelated stigma among HIV-positive older persons in Uganda-a mixed methods analysis," SAHARA-J: Journal of Social Aspects of HIV/AIDS, vol. 11, no. 1, pp. 126-137, 2014.

[57] J. Pulerwitz, A. Michaelis, E. Weiss, L. Brown, and V. Mahendra, "Reducing HIV-related stigma: lessons learned from horizons research and programs," Public Health Reports, vol. 125, no. 2, pp. 272-281, 2010.

[58] S. Takada, S. D. Weiser, E. Kumbakumba et al., "The dynamic relationship between social support and HIV-related stigma in rural Uganda," Annals of Behavioral Medicine, vol. 48, no. 1, pp. 26-37, 2014.

[59] D. Akena, S. Musisi, J. Joska, and D. J. Stein, "The association between AIDS-related stigma and major depressive disorder among HIV-positive individuals in Uganda," PLoS One, vol. 7, no. 11, Article ID e48671, 2012.

[60] B. Nattabi, J. Li, S. C. Thompson, C. G. Orach, and J. Earnest, "Between a rock and a hard place: stigma and the desire to have children people living among with HIV in northern Uganda," Journal of International AIDS Society, vol. 15, no. 2, Article ID 17421, 2012.

[61] G. Mburu, M. Ram, M. Skovdal et al., "Resisting and challenging stigma in Uganda: the role of support groups of people living with HIV," Journal of the International AIDS Society, vol. 16, no. 2, Article ID 18636, 2013.

[62] D. S. Batey, S. Whitfield, M. Mulla et al., "Adaptation and implementation of an intervention to reduce HIV-related stigma among healthcare workers in the United States: piloting of the FRESH workshop," AIDS Patient Care and STDs, vol. 30, no. 11, pp. 519-527, 2016.

[63] R. E. Stake, The Art of Case Study Research, Sage publications, Thousand Oaks, CA, USA, 1995.

[64] J. W. Creswell, Research Design: Qualitative, Quantitative and Mixed Methods Approaches, Sage Publications, Thousand Oaks, CA, USA, 2009.

[65] S. U. Arinze-Onyia, I. Modebe, and E. N. Aguwa, "Disclosure of HIV status by persons living with HIV/AIDS in their workplaces and post disclosure consequences on the patients," Journal of Experimental Research, vol. 3, no. 1, pp. 32-40, 2015.

[66] International Labour Organisation, Declaration on Fundamental Principles and Rights at Work: Discrimination (Employment and Occupation) Convention (No. 111), International Labour Organisation, Geneva, Switzerland, 1958.

[67] L. Brener, T. Broady, E. Cama, M. Hopwood, J. B. F. de Wit, and C. Treloar, "The role of social support in moderating the relationship between HIV centrality, internalised stigma and psychological distress for people living with HIV," AIDS Care, vol. 32, no. 7, pp. 850-857, 2020.

[68] K. Scott, C. Campbell, M. Skovdal, C. Madanhire, C. Nyamukapa, and S. Gregson, "What can companies do to support HIV-positive workers? Recommendations for medium- and large-sized African workplaces," International Journal of Workplace Health Management, vol. 6, no. 3, pp. 174-188, 2013.

[69] S. C. Kalichman, T. Heckman, A. Kochman, K. Sikkema, and J. Bergholte, "Depression and thoughts of suicide among middle-aged and older persons living with HIV-AIDS," Psychiatric Services, vol. 51, no. 7, pp. 903-907, 2000.

[70] S. E. Stutterheim, R. Brands, I. Baas, L. Lechner, G. Kok, and A. E. R. Bos, "HIV status disclosure in the workplace: positive and stigmatizing experiences of health care workers living with HIV," Journal of the Association of Nurses in AIDS Care, vol. 28, no. 6, pp. 923-937, 2017.

[71] C. Worthington, K. O’Brien, E. Zack, E. McKee, and B. Oliver, "Enhancing Labour force participation for people living with HIV: a multi-perspective summary of the research evidence," AIDS and Behavior, vol. 16, no. 1, pp. 231-243, 2012.

[72] S. N. Ssali, L. Atuyambe, C. Tumwine et al., "Reasons for disclosure of HIV status by people living with HIV/AIDS and in HIV care in Uganda: an exploratory study," AIDS Patient Care and STDs, vol. 24, no. 10, pp. 675-681, 2010.

[73] S. Neema, L. M. Atuyambe, B. Otolok-Tanga et al., "Using a clinic-based creativity initiative to reduce HIV related stigma at the infectious diseases institute, Mulago National Referral Hospital, Uganda," African Health Sciences, vol. 2, no. 12, pp. 231-239, 2012.

[74] E. Cama, L. Brener, S. Slavin, and J. Wit, "The relationship between negative responses to HIV status disclosure and psychosocial outcomes among people living with HIV," Journal of Health Psychology, vol. 25, no. 4, pp. 538-544, 2017.

[75] E. Cama, L. Brener, S. Slavin, and J. de Wit, "The relationship between negative responses to HIV status disclosure and psychosocial outcomes among people living with HIV," Journal of Health Psychology, vol. 25, no. 4, pp. 538-544, 2020.

[76] C. A. Mills and I. Govender, "Knowledge, attitude and practices of employers should they discover that their domestic worker is HIV positive: Cashan, Rustenburg," Occupational Health Southern Africa, vol. 22, no. 1, pp. 10-17, 2016.

[77] UMoGLSD, National Policy on HIV/AIDS and the World of Work, UMoGLSD, Kampala, Uganda, 2007.

[78] E. L. Corbett, E. Dauya, R. Matambo et al., "Uptake of workplace HIV counselling and testing: a cluster-randomised trial in Zimbabwe," PLoS Medicine, vol. 3, no. 7, Article ID e238, 2006.

[79] ICAP, Approach to Strategic HIV Testing, ICAP, London, UK, 2017.

[80] S. Shamu, J. Slabbert, G. Guloba et al., "Linkage to care of HIV positive clients in a community based HIV counselling and testing programme: a success story of non-governmental 
organisations in a South African district," PLoS One, vol. 14, no. 1, Article ID e0210826, 2019.

[81] E. Kinyanda, S. Hoskins, J. Nakku, S. Nawaz, and V. Patel, "The prevalence and characteristics of suicidality in HIV/ AIDS as seen in an African population in Entebbe district, Uganda," Bio Med Central Psychiatry, vol. 12, no. 63, 2012.

[82] NAFOPHANU, The People Living with HIV Stigma Index, Country Assessment, Uganda, NAFOPHANU, Kampala, Uganda, 2013.

[83] L. Schlebusch and R. D. Govender, "Elevated risk of suicidal ideation in HIV-positive persons," Depression Research and Treatment, vol. 2015, Article ID 609172, 6 pages, 2015.

[84] ILO, An ILO Code of Practice on HIV/AIDS and the World of Work, ILO, Geneva, Switzerland, 2001.

[85] D. Grabowski, J. Aagaard-Hansen, I. Willaing, and B. B. Jensen, "Principled promotion of health: implementing five guiding health promotion principles for research-based prevention and management of diabetes," Societies, vol. 7, no. 2, pp. 1-15, 2017.

[86] G. Pavlekovic, D. Donev, and Z. Lijana, "Concepts and principles in health promotion," Forum for Public Health Cooperation Stability Pact for South Eastern Europe Project, vol. 4, 2008.

[87] E. L. Kelly, P. Moen, and E. Tranby, "Changing workplaces to reduce work-family conflict: schedule control in a white-collar organization," American Sociological Review, vol. 76, no. 2, pp. 265-290, 2011. 